www.jmscr.igmpublication.org

Impact Factor (SJIF): 6.379

Index Copernicus Value: 71.58

ISSN (e)-2347-176x ISSN (p) 2455-0450

crossref DOI: https://dx.doi.org/10.18535/jmscr/v6i4.164

Journal Of Medical Science And Clinical Research

IGM Publication

An Official Publication of IGM Publication

\title{
Serum CRP: A Marker of Bowel Gangrene in Acute Intestinal Obstruction
}

\section{Authors \\ Dr Dileep Singh Thakur M.S. ${ }^{1}$, Dr Chandan Tiwari M.S. ${ }^{2}$, Dr Uday Somashekar M.S.,DNB ${ }^{3}$, Dr Reena Kothari M.S ${ }^{4}$, Dr Dhananjaya Sharma M. S., PhD, DSc, FRCS (Glasgow), FRCS (Ireland), FRCS-T (Hon), FRCS (Edin) ${ }^{5}$}

\footnotetext{
${ }^{1}$ Associate Professor, Department of Surgery, N.S.C.B. Medical College and Hospital, Jabalpur, India

Contact: +91-9826155052, Email: dileepthakur75@gmail.com

${ }^{2}$ Senior Resident, Department of Surgery, N.S.C.B. Medical College and Hospital, Jabalpur, India

${ }^{3}$ Associate Professor, Department of Surgery, N.S.C.B. Medical College and Hospital, Jabalpur, India

Email: udaysomashekar@gmail.com, Contact: 9425324514

${ }^{4}$ Associate Professor, Department of Surgery, N.S.C.B. Medical College and Hospital, Jabalpur, India

Email: reena.kothari00@gmail.com, Contact: 9827099019

${ }^{5}$ Professor and Head, Dept of General Surgery, N.S.C.B. Medical College and Hospital,Jabalpur, India

Contact: +91-9425156445, Email: dhanshar@gmail.com
}

Corresponding Author

Dr Chandan Tiwari

Contact: + 91-8085201097, Email: drchandan80@ gmail.com

\begin{abstract}
Acute Intestinal Obstruction remains one of the most common intra-abdominal problem faced by General Surgeon Its early recognition and aggressive treatment can prevent irreversible ischaemia and trans-mural necrosis, thereby reducing mortality and morbidity. Overall mortality rate for bowel obstruction rises many a fold if gangrene in obstructed segment ensues, which is $3 \%$ in simple obstruction compared to $30 \%$ in strangulated obstruction. Early resuscitation and surgical exploration may minimize morbidity and mortality in such patients. A number of clinical, haematological, biochemical or radiological marker to differentiate between simple and strangulated intestinal obstruction. Research are ongoing to clearly define their diagnostic use and potential role in determining which patient should be managed surgically. C-reactive protein is acute phase reactant synthesised in liver whose level rapidly increases in response to stress, tissue Injury, ischaemia, and other inflammatory conditions. CRP is used as marker of cardiac ischaemia in acute coronary syndromes and its prognosis, thus it is likely to be elevated in comparatively greater level in bowel ischaemia. We conducted study on 83 patients with diagnosis of acute intestinal obstruction which were greater than 14 years of age to evaluate usefulness of CRP. Semi quantitative CRP evaluation was done in subjects at time of presentation and preoperatively. Then statistical test chi square test and Pearsons correlation coefficient was applied on CRP results. On completion of study and application of statistical tests it was found that $60 \%$ of patients with strangulated bowel obstruction have a positive serum CRP and was not raised in $73.6 \%$ patients with simple obstruction. The chi-square value was 9.121 and p-value was also significant $(p=0.003)$.The mean CRP levels in patients of intestinal obstruction on admission was 8.80(+/-4.007) with non gangrenous bowel and was 20.16(+/-10.6097) with gangrenous bowel. It was statistically significant with a $p$ value of 0.001. However the preoperative CRP level in patients with non gangrenous bowel was 12.68(+/-6.131) while with gangrenous gut was 20.80(+/-10.54) and this also showed correlation which was statistically significant with a $p$ value of $0.01(p<0.05)$. The Pearson's correlation coefficient between serum CRP on admission and length of gangrenous bowel were observed to be 0.10 and shows a positive but weak correlation and this was statistically significant. So it appear that serum CRP can be used as objective indicator to diagnose irreversible bowel ischaemial gangrene, as serum CRP can be measured noninvasively, is readily available, cheaper, needs no expertise and results are reproducible.
\end{abstract}




\section{Introduction}

Intestinal obstruction was recognised, described and treated from the time of Hippocrates. It remains one of the most common intra-abdominal problem faced by General Surgeon. Its early recognition and aggressive treatment can prevent irreversible ischaemia and trans-mural necrosis, thereby reducing mortality and morbidity. It has been estimated that $1 \%$ of all hospitalisation, $3 \%$ of emergency surgical admissions and 4\%of major celiotomies are secondary to bowel obstruction or procedure requiring adhesiolysis.

Overall mortality rate for bowel obstruction rises many fold if gangrene in obstructed segment ensues, which $3 \%$ in simple obstruction is compared to $30 \%$ in strangulated bowel obstruction.

Early resuscitation and surgical exploration may minimize morbidity and mortality in such patients. Preoperative assessment of presence or absence of strangulation by available patient's parameter is correct only in $70 \%$ cases while $30 \%$ come out as surprise.There arises the need of objective indicator if intestinal ischaemia and gangrene in intestinal obstruction patients which can help in decision making of continuing conservative treatment with expectation of spontaneous resolution of obstruction or going for surgical intervention. If a reliable indicator is available then decision making might become very easy to prompt surgery and reduce morbidity and mortality.

C-reactive protein is acute phase reactant synthesised in liver whose level rapidly increases in response to stress, tissue Injury, ischaemia, and other inflammatory conditions.CRP has many properties which make it good marker for diagnostic workup of inflammatory or infectious disease ,Induction of CRP is rapid with half-life $(19 \mathrm{hrs})$ and there is no diurnal variation by contrast with other acute phase reactants, CRP is also used as marker of cardiac ischaemia in acute coronary syndromes and its prognosis, thus it is likely to be elevated in comparatively greater level in bowel ischaemia,
In this study we evaluated the Preoperative level of CRP in patients undergoing surgery for intestinal obstruction with or without associated bowel ischaemia

\section{Material and Methods}

The prospective study was conducted in department of surgery of NSCB medical college Jabalpur MP during a period of 1 year i.e. from October 2016 to September 2017.

Patients of Acute Intestinal Obstruction greater than 14 years of age who were managed surgically were included in study.

Pre-operative evaluation criteria includes

- Clinical features-

1. Pulse rate ,Respiratory rate,blood pressure,

2. Pain and its nature

3. Blood mixed stools

4. Abdominal findings-guarding, rigidity

5. Digital rectal examination.

- Haematological and biochemical profile-

1. Haemoglobin

2. TLC

3. DLC

4. Platelet count

5. Serum creatinine

- Radiological profile-

1. X-ray scout abdomen

2. USG whole Abdomen

- C-reactive protein level on admission and preoperatively were done.

- Per operative findings of patients were recorded to assess the presence of ischaemia or gangrene.All observations were evaluated statistically.

\section{Exclusion criteria}

1. Connective tissue disorder

2. Rheumatoid arthritis and acute rheumatic fever

3. Known case of malignancy

4. Tuberculosis and other acute and chronic inflammatory conditions.

5. Active liver disease

6. Patients on OCPs

7. Pneumococcal pneumonia 
8. Myocardial infarction

Semi quantitative estimation of CRP was done in serum based on principle of agglutination. The test serum was mixed with CRP latex reagent and allowed to react. If CRP concentration was greater than $0.6 \mathrm{mg} / \mathrm{dl}$ a visible agglutination is observed. If CRP concentration was less than $0.6 \mathrm{mg} / \mathrm{dl}$ then no agglutination is observed.

\section{Serum Quantitative Method}

Agglutination in the highest serum dilution corresponds to amount of CRP in $\mathrm{mg} / \mathrm{dl}$ present in the test specimen.

Concentration of CRP is calculated as follows-

$\mathrm{Crp}(\mathrm{mg} / \mathrm{dl})=\mathrm{SXD}$

Where $S=$ Sensitivity of reagent

$\mathrm{D}=$ highest dilution of serum showing agglutination.

\section{Observations}

During study period total of 83 patients were included and there details were filled in proforma after study period a master chart was made and then statistical test were applied i.e chi-square test and Pearson correlation coefficient were applied. On application of these test following observations were found

- $86.66 \%$ of patients with gangrenous bowel were $<60$ years of age and only $13.33 \%$ patients were $>60$ years.

- $13.3 \%$ of patients with gangrenous bowel present with fever however $86.7 \%$ patients were afebrile. ( $p>0.05)$.

- All patients with gangrenous bowel presented within one week and none after that. The chi square value was 0.025 $(<0.05)$ which was significant. The mean duration of presentation of patients with strangulation intestinal obstruction was 3.070 days.

- The most common cause of obstruction was adhesions accounting for $39.8 \%$ followed by obstructed hernia (18.1\%), bands $(16.9 \%)$, volvulus $(8.4 \%)$, stricture $(4.8 \%)$ and miscellaneous $(8.4 \%)$.
- $43.3 \%$ patients with gangrenous bowel has neutrophilic leucocytosis and only $24.5 \%$ patients with non-gangrenous obstruction had neutrophilic leucocytosis. $(\mathrm{p}=0.076)$.

- $60 \%$ of patients with strangulated bowel obstruction have a positive serum CRP value while it was not raised in $73.6 \%$ patients with simple obstruction. The chisquare value was 9.121 and $p$-value was also significant $(\mathrm{p}=0.003)$

- The mean CRP levels in patients of intestinal obstruction on admission was 8.80 with non-gangrenous bowel and was 20.16 with gangrenous bowel $(p=0.001)$. Also the preoperative CRP level in patients with non-gangrenous bowel was 12.68 while with gangrenous gut was 20.80 and this also showed correlation which was statistically significant with a $\mathrm{p}$ value of $0.01(\mathrm{p}<0.05)$.

- The preoperative serum CRP level and its correlation with length of bowel segment was 0.065 which came out to be statistically in significant ( $\mathrm{p}$ value $>0.05$ ).

- The Pearson's correlation coefficient between bowel gangrene and serum CRP level on admission came out strong i.e. $\mathrm{p}$ value was $0.002(<0.05)$ indicates strong correlation between them.

- The serum CRP level preoperatively in patients with bowel ischaemia also showed a strongly positive and significant correlation. This correlation was statistically significant with $\mathrm{p}$ value of 0.01 .

The preoperative serum CRP level was positive in 18 pts with gangrenous segment while negative in 12 pts with gangrenous segment, while it is positive in 14 patients with non gangrenous bowel and negative in 39 pts with non gangrenous bowel. This make it $60.00 \%$ sensitive and $73.60 \%$ specific, and its PPV came out to be 56.30 with diagnostic accuracy of $68.70 \%$. 
Correlation between Serum CRP and Bowel Gangrene

\begin{tabular}{|c|c|c|c|}
\hline $\begin{array}{c}\text { CRP } \\
\text { (PREOP) }\end{array}$ & $\begin{array}{c}\text { NON GANGRENOUS } \\
\text { BOWEL }\end{array}$ & $\begin{array}{c}\text { GANGRENOUS } \\
\text { BOWEL }\end{array}$ & TOTAL \\
\hline NEGATIVE & 39 & 12 & 51 \\
& $(73.6 \%)$ & $(40.0 \%)$ & $(61.4 \%)$ \\
\hline POSITIVE & 14 & 18 & 32 \\
& $(26.4 \%)$ & $(60.0 \%)$ & $(38.6 \%)$ \\
\hline & 53 & 30 & 83 \\
TOTAL & $(100 \%)$ & $(100 \%)$ & $(100 \%)$ \\
\hline
\end{tabular}

Serum CRP In Patients with and Without Intestinal Gangrene

\begin{tabular}{|l|c|c|c|}
\hline \multirow{2}{*}{ INTESTINE } & \multirow{2}{*}{ CRP } \\
\cline { 3 - 4 } & & $\begin{array}{c}\text { ON } \\
\text { ADMISSION }\end{array}$ & $\begin{array}{c}\text { PRE } \\
\text { OPERATIVE }\end{array}$ \\
\hline \multirow{3}{*}{ NON } & MEAN & 8.80 & 12.68 \\
\cline { 2 - 4 } GANGRENOUS & S.D. & 4.00727 & 6.13174 \\
\cline { 2 - 4 } & $\mathrm{N}$ & 12 & 14 \\
\hline \multirow{4}{*}{ GANGRENOUS } & MEAN & 20.16 & 20.80 \\
\cline { 2 - 4 } & S.D. & 10.60975 & 10.54 \\
\cline { 2 - 4 } & $\mathrm{N}$ & 15 & 18 \\
\hline
\end{tabular}

\section{Results}

The study showed that the mean serum level in patients of acute intestinal obstruction with non gangrenous bowel at the time of admissions was 8.80 while that immediately prior to surgery was 12.68. The mean serum CRP level in gangrenous bowel has been found to be relatively high ie 20.16 at time of admission and 20.80 prior to surgery.

The result was statistically significant with a pvalue of 0.001 at values at time of admission and p-value was 0.01 prior to surgery. This serve to state that the level of CRP is more significant when evaluated at time of admission and serial titres of serum CRP titres has also found to correlate.

In this study the sensitivity of preoperative CRP level was $60 \%$ with specificity was $73.60 \%$. it had positive predictive value of $56.30 \%$ and a diagnostic accuracy of $68.70 \%$.

So also the correlation between the level of CRP on admission and the length of gangrenous bowel found preoperatively was 0.100 showed a positive but weak correlation also this was statistically insignificant with a $p$ value 0.723 , the correlation between the preoperative level of crp and length of gangrenous bowel was 0.065 which was also positive but weak and statistically insignificant with $\mathrm{p}$ value 0.79 .
The study had shown that patients with a intestinal gangrene presented early ( $<1$ week) with a mean duration of 3.74 days. So it appears that a strong degree of suspicion should be kept in such patients as this would help in early diagnosis and prompt treatment if intestinal ischaemia/gangrene occurs.

So it appear that serum CRP can be used as objective indicator to diagnose irreversible bowel ischaemia/ gangrene, as serum CRP can be measured noninvasively ,is readily available, cheaper, needs no expertise and results are reproducible.

As serum CRP was increased significantly in patients with bowel gangrene so it is likely that it could be elevated just before gangrene has set in .so it appears that serial estimation of serum CRP level in patient of acute intestinal obstruction might help to diagnose intestinal ischemia at earliest and prompt early treatment thus reducing the mortality and morbidity.

\section{Discussion}

The primary concern in the patients with an intestinal obstruction is the possibility of ischaemia. Clinical judgement and laboratory findings have been unreliable for early detection of intestinal vascular compromise. As mortality rates may increase up to $30 \%$ in cases of strangulated bowel obstruction so early detection 
of this condition is of prime importance in bowel obstruction. But neither parameter nor combination of parameters can diagnose ischaemia. Few parameters which can indicate pending or established ischaemia and development of peritonism or peritonitis indicate overt infarction and/or perforation are

- Fever

- Tachycardia

- Leucocytosis

- Continuous abdominal pain

- Shock

- Peritonitis

The presence of continuous abdominal pain, tachycardia, leucocytosis, peritoneal signs and fever has an $82 \%$ predictive value for strangulated obstruction while any 4 of above signs might give $100 \%$ predictive value for strangulation in obstruction.

Some studies done by few researchers like Dums Grons Dalsing and Grosfeld (1985) studied phosphate level in patients with acute intestinal infarction as proved by laparotomy ,serum phosphate was increased preoperatively in $94.4 \%$ of cases, False positive results were not recorded. Delaney O'Neil et $\mathrm{al}^{(10)}$ assessed Alphaglutathione-s -transferase as a marker of intestinal ischaemia. it plays a crucial role in cellular homeostasis the alpha isomer is specific for small bowel and liver. Alpha-GST was significantly increased in patients with mesenteric ischaemia i.e. a threshold of $>4 \mathrm{ng} / \mathrm{ml}$ of alpha GST was $100 \%$ sensitive and $86 \%$ specific for mesenteric ischaemia.

Kanda fuji et al ${ }^{(11)}$ evaluated the role of Intestinal Fatty Acid Binding Protein as a diagnostic marker for mesenteric ischaemia in human. Study was conducted on rats indicates that FABP was a serum marker reflecting bowel ischaemia. Similarly in humans also they found significantly higher level of FABP in mesenteric ischaemia.

Okuda et al (2001) ${ }^{(12)}$ conducted a study using Pulse Doppler Sonography (PDS) for detection of strangulation in small bowel obstruction by evaluating haemodynamic in superior mesenteric artery. They measured peak systolic velocity and end diastolic velocity with mean average velocity and calculated Resistive index. They observed that significant increase in EDV and RI in SMA in the strangulated obstruction compared with simple obstruction.

CT evidence of intestinal ischemia, strangulation, or vascular compromise are

- Pneumatosis intestinalis,

- Bowel wall thickening,

- Portal venous gas,

- Generalized ascites,

- Non-enhancement of bowel wall.

Richard and associates ${ }^{(14)}$ used a Superconducting Quantum Interference device (SQUID) magnetometer to non-invasively detect mesenteric ischaemia. Intestinal ischaemia is associated with changes in basic electrical rhythm of small intestine.

CRP a member of pentraxin protein family discovered in 1930 as a protein reacting with Cpolysaccharide of cell wall of streptococcus pneumoniae. Phosphoryl choline residue of the Cpolysaccharide provide a major determinant for interaction with CRP. Later it was found that its level were also increased in other than pneumococcal infection especially when there is tissue necrosis.

CRP is acute phase reactant protein produced by liver with molecular weight $118-144 \mathrm{kDa}$ with substantial carbohydrate content. Its normal serum values are about $100 \mathrm{ng} / \mathrm{ml}$ at birth, $170 \mathrm{ng} / \mathrm{ml}$ in children and 470-1340 ng/ml in adults. Normal value of crp vary from lab to lab but generally there is no crp detectable in blood(less than $0.6 \mathrm{mg} / \mathrm{dl})$.

Ligand bound crp activates the classical complement pathway, binds to immunoglobulin receptors on immune cell and activates cytokine production and complement related inflammatory reaction that may exacerbate inflammatory ischaemic injury. The rate of synthesis and secretion increases within hours of an acute injury, onset of inflammation, tissue necrosis and may reach up to 100 folds or more. Moderately 
increased plasma CRP concentration are found in smokers, under conditions of atherosclerosis, psychological stress, diabetes and obesity.

Elevated CRP level is unequivocal evidence of active tissue damage process.

CRP is a sensitive acute phase protein so used extensively in diagnosis, screening and in progress of number of inflammatory, infectious and noninfectious conditions causing tissue inflammation.

CRP is used in post-operative surveillance as is level invariably rise after major surgery but falls to normal within 7-10 days. Absence of this fall indicates possible septic or inflammatory postoperative complications.

CRP is also considered to be directly involved in coronary plaque atherogenesis. Elevated CRP levels independently predict adverse cardiac events. Elevated CRP is independent predictor of cardiac death, acute myocardial infarction and congestive cardiac failure.

CRP is a biochemical predictor of more severe disease in patients with definitive rheumatoid arthritis of relatively recent onset.

CRP is used as serum marker of neonatal sepsis. Berger C, Uehienger J et al ${ }^{(22)}$ in 1955 done a study on 195 sick neonates suspected of septicaemia during the first 3 days of life the sensitivity and specificity was found to be $75 \%$ and $86 \%$ respectively.

CRP is also increased in Acute Rheumatic fever. crp is uniformly increased in patients with acute rheumatic fever on steroids. Absence of CRP is strongly against the diagnosis of disease.

Nehmat Hakan et $\mathrm{al}^{(24)}$ conducted an experimental study in rats and found that CRP level increase with the severity of bacterial translocation in acute intestinal obstruction but do not permit discrimination between simple and strangulated obstruction.

\section{Summary and Conclusion}

The result can be summarized as follows -

1) Serum CRP level appears to be an objective predictor of intestinal gangrene/ischaemia in patients with acute intestinal obstruction.
2) Serum CRP level on admission in patients with gangrenous bowel were $20.16 \mathrm{mg} / \mathrm{dl}$ and with non-gangrenous bowel were 8.80.the correlation between them was statistically significant with a $p$ value of 0.001 .

3) Serum CRP level preoperatively in patient with gangrenous bowel was $20.80 \mathrm{mg} / \mathrm{dl}$ and non gangrenous bowel was $12.68 \mathrm{mg} / \mathrm{dl}$.the correlation between them was statistically significant.

4) Larger study with large no of patients and serial quantitative measure of serum CRP are further required to prove the results.

\section{Bibliography}

1. Maingot's abdominal operations; Michael J Zinner, Stanley W Ashley, Mac Graw Hill Publication $11^{\text {th }}$ Edition 479-482.

2. Miller G,Boman J,Shrier J et al .Natural history of patient with Bowel obstruction. Br J Surgery 2000; 87:1240-1247.

3. Sarr MG, Bulkely GB, ZuidemaGD; Preoperative recognition of intestinal obstruction: Preoperative evaluation of diagnostic capability. Am J Surgery145:176-182,1983.

4. Maingot's abdominal operations .Michael J Zinner, Stanley W Ashley, Mac Graw Hill Publication $11^{\text {th }}$ Edition501-502.

5. Clinical diagnosis and management by laparotomy methods. Todd Samford, Davidson John Bernard Henry, Saunders publication $17^{\text {th }}$ edition $212-213$.

6. Engelhart $\mathrm{T}$ and Cuthbertson BH. Markers of myocardial damage and inflammation in unstable coronary artery disease. N Engl J Med 2001 :344:688-689.

7. Griselli $\mathrm{M}$, Herbert $\mathrm{J}$, Hutchinson WL, Taylor KM ,Sohail M, Krauz T and Pepys MB.CRP and complements are important mediators of tissue damage in acute myocardial infarction Exp Med ;1999:190:1733-1740. 
8. Bailey and Love's.Short practice of surgery Russell Norman S William and Christopher Bulstrode; Arnold publications $23^{\text {rd }}$ edition,1060-1061.

9. Sarr MG, Bulkily GB, Zuidema GB; preoperative recognition of intestinal strangulation obstruction, Prospective evaluation of diagnostic capability; Am j surgery;145 176-181,1983.

10. Delaney CP, O Neil $S$ et al .Plasma concentration of Glutathione $\mathrm{S}$ Transferase. Isoenzyme in patients with intestinal ischaemia; British journal of Surgery, 1999.

11. Kanda T,Fuji $\mathrm{H}$, Tani $\mathrm{T}$ et al :Intestinal Fatty Acids Binding protein is a useful diagnostic marker of mesenteric infarction in humans.Gastroenterology: 1996;100; 339-343.

12. Ogata M, Imai S, Hosotani $\mathrm{R}$ et al; Abdominal Ultrasonography for the diagnosis of strangulation in small bowel obstruction: Br J Surgery 1994 ;81 421424.

13. Baerga -Valera Y. Small bowel obstruction .In Kelly KA, Sarr MG, Hinder RA eds; Mayo clinic,gastrointestinal surgery, $1^{\text {st }}$ edition Philadelphia :PA Saunders $2004,421-437$.

14. Richard WO, Gauraud GI, Allos SH et al ,Non invasive diagnosis of mesenteric ischemia using SQUID magnetometer,Ann Surgery ;1995:221 695-705.

15. Pepys MB, Berger A, The renaissance of $C$ -reactive protein ;BMJ 2001322 4-5

16. Kaplan MH, Volkanis JE, Interaction of CRP with complement system, J immunol 1974112 2135-2147.

17. Nijmeijer R, Lagrand WK, Lubbers YT et al; CRP activates complement in infarcted myocardium. Am J Pathol 2003163 269275.

18. Meier Ewert HK, Ridker PM et al .Absence of diurnal variation of CRP in healthy human subjects. Clinical Chemistry: 2001: 47:426-430.

19. PerdizP ,Wachner $\mathrm{N}$ et al .Circadian variation of human acute phase response.Arch Med Res 1996:27-157-163.

20. Koeing $W$ et al .Predicting risk and treatment benefit in atherosclerosis; International journal Cardiology.205:98 (2)199-206.

21. Rheumatoid Arthritis -Edward D Harris J.109- 110.

22. Berger $C$,Uehinger $J$ et al. Comparison of WBC count and CRP. With differential in neonates at risk of septicaemia,.European Journal Paediatrics 1995 154; 138-144.

23. Essential of paediatrics. O P Ghai,Paul VK Mehta publications, $5^{\mathrm{TH}}$ edition 275-276.

24. NehmetHC,Hedef $\mathrm{O}$ et al.CRP may be marker of bacterial translocation in experimental intestinal obstruction. ANZ Journal of Surgery.2004 74:900.

25. Tulip CRP,Diagnostic kit. 